medRxiv preprint doi: https://doi.org/10.1101/2021.07.19.21260787; this version posted July 22, 2021. The copyright holder for this preprint (which was not certified by peer review) is the author/funder, who has granted medRxiv a license to display the preprint in perpetuity.

It is made available under a CC-BY-ND 4.0 International license .

\title{
1 Cognitive profile of mild behavioral impairment in Brain Health Registry participants
}

2 F. Kassam ${ }^{1}$, H. Chen $\mathrm{PhD}^{1}$, R.L. Nosheny $\mathrm{PhD}^{2}$, A. McGirr MD PhD ${ }^{3}$, T. Williams ${ }^{4}$, Nicole Ng, 3 Monica Camacho, R.S. Mackin $\mathrm{PhD}^{2}$, M.W. Weiner MD ${ }^{4}$, Z. Ismail MD ${ }^{1,3^{*}}$

$5 \quad{ }^{1}$ University of Calgary, Hotchkiss Brain Institute.

$6 \quad 2$ University of California, San Francisco, Department of Psychiatry.

$7 \quad{ }^{3}$ University of Calgary, Department of Psychiatry

$8{ }^{4}$ University of California, San Francisco, Departments of Radiology and Biomedical Imaging,

9 Medicine, Psychiatry, and Neurology

$10 *$ Corresponding author:

11 Zahinoor Ismail

123280 Hospital Dr. NW Calgary AB

13 Canada T2N 4Z6

$14 \quad 403-210-6900$

15 ismailz@ucalgary.ca

16 Word Count: 2733

17

\section{KEYWORDS}

20 Mild Behavioral Impairment (MBI), Brain Health Registry, Study Partner, Informant Rated

21 Scales, Neuropsychological Testing, Mild Cognitive Impairment (MCI), Neuropsychiatric

22 Symptoms (NPS)

\section{RESEARCH IN CONTEXT}

25 Systematic review: The authors searched MEDLINE and Google Scholar for studies linking

26 Mild Behavioral Impairment (MBI) and cognition in non-demented older adults. Most studies

27 have utilized transformed Neuropsychiatric Inventory scores to assess MBI, and relatively few

28 using the novel MBI-checklist (MBI-C), with the largest study using self-report. Exploration of 
29 informant reports of MBI is important due to impaired insight that may accompany

30 neuropsychiatric symptoms.

31 Interpretation: Older adults with online, informant reported MBI had poorer performance in

32 memory and executive function measured using online neuropsychological testing compared to

33 those without MBI. These findings are consistent with the current literature and suggest that the

34 MBI-C may serve as a marker for poorer cognitive performance.

35 Future directions: Our data support the role of online testing of cognition and behavior for risk

36 assessment. This approach to evaluate behavior and cognition can be explored further, to

37 determine if it is a scalable, online approach to detection of neurodegenerative disease. 


\section{Abstract}

INTRODUCTION: Dementia assessment includes cognitive and behavioral testing with informant validation. Conventional testing is resource intensive, with uneven access. Online unsupervised assessments could reduce barriers to risk assessment. We interrogated the relationship between informant-rated behavioral changes and neuropsychological test performance in older adults in the Brain Health Registry.

METHODS: Participants completed online unsupervised cognitive tests, and informants completed the Mild Behavioral Impairment Checklist via a Study Partner portal. Cognitive performance was evaluated in $\mathrm{MBI}+/$ - individuals, as was the association between cognitive scores and MBI symptom severity.

RESULTS: Mean age of the 499 participants was $67,61 \%$ of which were female. MBI+ participants had lower working memory and executive function test scores. Lower cognitive test scores associated with greater MBI burden.

DISCUSSION: Our findings support the feasibility of remote, informant-reported behavioral assessment and support its validity by demonstrating a relationship to cognitive test performance using online unsupervised assessments for dementia risk assessment.

63 
medRxiv preprint doi: https://doi.org/10.1101/2021.07.19.21260787; this version posted July 22, 2021. The copyright holder for this preprint (which was not certified by peer review) is the author/funder, who has granted medRxiv a license to display the preprint in perpetuity.

It is made available under a CC-BY-ND 4.0 International license .

\section{Background}

Access to dementia assessments is uneven in North America and across the world. This disparity

67 has important clinical repercussions, particularly in regions where specialized resources are

68 limited, and identification is delayed until later manifestations. The development of unsupervised

69 platforms that do not require highly trained administrators may resolve this dual impasse and

70 improve clinical outcomes. Moreover, they may create a low-cost recruitment infrastructure for

71 early intervention trials, where no disease-modifying drug in Alzheimer's disease (AD) has met

72 all primary endpoints ${ }^{1,2}$ in part due to poor recruitment of individuals without overt impairment

73 or who are in the earliest stages of disease $\mathrm{e}^{3,4}$. Advances in online services open the possibility of

74 assessment portals in any region with an internet connection, for any individual with access to

75 the internet and a computing device. Moreover, cognitive tests have been computerized and can

76 be delivered without an administrator, and with convergent validity with those administered in

77 tertiary cognitive assessment centers $^{5-9}$.

79 The addition of behavioral assessments to online platforms may provide additional relevant

80 information. Neuropsychiatric symptoms (NPS) such as agitation, anxiety, apathy, depression,

81 and psychosis are considered core features of dementia and are associated with poorer patient

82 outcomes ${ }^{10}$. However, NPS can often precede cognitive symptoms, including in $30 \%$ of those

83 who develop $\mathrm{AD}^{11}$. Mild behavioral impairment (MBI) is a pre-dementia neurobehavioral

84 syndrome characterized by the de novo emergence and persistence of NPS in older adults

85 representing a change from longstanding patterns of behavior ${ }^{12}$. MBI is associated with amyloid,

86 tau, and neurodegeneration ${ }^{13-19}$, and a greater risk of incident cognitive decline and dementia ${ }^{20-26}$.

87 Incorporating MBI into screening may provide a complementary approach to early detection ${ }^{4}$. 
medRxiv preprint doi: https://doi.org/10.1101/2021.07.19.21260787; this version posted July 22, 2021. The copyright holder for this preprint (which was not certified by peer review) is the author/funder, who has granted medRxiv a license to display the preprint in perpetuity.

It is made available under a CC-BY-ND 4.0 International license .

88 However, informant information is often required to validate the syndrome, and structured assessment tools suitable for widespread dissemination through unsupervised platforms have

90 only recently been developed. The Mild Behavioral Impairment Checklist (MBI-C) incorporates

91 informant information and is the validated case ascertainment instrument developed specifically

92 to capture MBI in accordance with the criteria developed by the International Society to Advance

93 Alzheimer's Research and Treatment-Alzheimer's Association (ISTAART-AA) ${ }^{27-30}$. Translated

94 into over 20 languages, the MBI-C may also allow a broader reach for obtaining online

95 informant reports of behavioral change.

97 The aim of this study was to investigate informant-based MBI in an online unsupervised

98 platform, the Brain Health Registry (BHR), capable of assessing early dementia risk markers ${ }^{31}$.

99 We determined the utility of the BHR for converging assessments of cognitive and behavioral

100 symptoms using neuropsychological testing and informant-reported MBI-C. We hypothesized

101 that participants with MBI+ status would have poorer cognitive performance measured by the

102 Lumos test battery. We further hypothesized that individuals with poorer memory, executive

103 function, processing speed, and inhibitory control would have a higher burden of MBI

104 symptoms.

105

106

\section{Methods}

$107 \quad 2.1$ Brain Health Registry

108 The $\mathrm{BHR}^{31}$ is an internet-based public registry and cohort that recruits participants using a

109 variety of methods including a website, social media, brochures, and online advertising. All

110 participants are required to give informed consent with an online consent form. Upon completion 
111 of the consent form, participants may complete questionnaires regarding personal and family

112 medical history, early childhood history, sleep quality, diet, quality of life scales, psychiatric

113 symptomatology, as well as online cognitive testing via Lumosity ${ }^{32}$, CogState ${ }^{33}$, or Memtrax ${ }^{34}$

114 tests. Additionally, study partners of BHR participants can register on the BHR study partner

115 portal, on which informant-rated measures are completed ${ }^{35}$.

117 2.2 Study Participants

118 Participants were included if: 1) Lumosity cognitive tests were completed; and 2) their informant

119 completed the MBI-C via the BHR study partner portal within a year of the cognitive tests.

120 Participants were excluded if they reported: 1) developmental or learning disorders; 2)

121 neurological conditions such as movement disorders, multiple sclerosis, traumatic brain injury;

122 3) current or past psychiatric diagnoses including schizophrenia, major mood or anxiety

123 disorders, or PTSD.

$125 \quad 2.3$ Study Variables

\subsubsection{Lumosity online Forward Memory Span}

127 The assessment of Forward Memory Span is based on the Corsi block-tapping tasks ${ }^{36}$. The

128 participant is asked to recall the sequence of circles in the same order it was presented. The

129 length of the sequence increases by one every two trials. The session comes to an end when the

130 participant records two incorrect answers at the same span level. This task is used as a measure

131 of visual short-term memory and attention. 
medRxiv preprint doi: https://doi.org/10.1101/2021.07.19.21260787; this version posted July 22, 2021. The copyright holder for this preprint (which was not certified by peer review) is the author/funder, who has granted medRxiv a license to display the preprint in perpetuity.

It is made available under a CC-BY-ND 4.0 International license .

134 The Reverse Memory Span task is a slightly altered version of the original Corsi block-tapping

135 tasks. It is identical to the forward visual memory span assessment, with the exception that the

136 participant is asked to recall the sequence of circles in the reverse order. This reverse task is used

137 as a measure of visual working memory and attention.

\subsubsection{Lumosity online Trail Making Test B}

140 In Trail Making Test (TMT) B, blue circles (numbered 1 to 12) and capital letters (A to L) are

141 arranged in 6 possible layouts with non-overlapping spatial locations. The participant must

142 alternate between numbers and letters for this task, clicking in increasing order. When the blue

143 circle is clicked, it turns orange and a straight line appears to connect the circles. The timer for

144 the task begins when the participants clicks the first circle. If the participant records an incorrect

145 click, an X appears on their screen and they are required to go back to the previous circle. For

146 this study, we included the response time and number of errors as measures of processing speed

147 attention and sequencing ability.

\subsubsection{Lumosity online Go/No-Go}

150 In the Go/No-Go assessment, participants are presented with target pictures and distractor

151 stimuli. The target picture is chosen from a set of photos of fruit. Each stimulus appears after a

152 random delay between 1000 and $3000 \mathrm{~ms}$ to discourage anticipatory responding. The participant

153 is instructed to respond as quickly as possible within $1500 \mathrm{~ms}$. The assessment ends when a

154 participant responds to ten "Go" trials. If the participant submits three incorrect responses

155 (responding to "no-go" or failing to respond to "go"), the participant will restart the task. The 
medRxiv preprint doi: https://doi.org/10.1101/2021.07.19.21260787; this version posted July 22, 2021. The copyright holder for this preprint (which was not certified by peer review) is the author/funder, who has granted medRxiv a license to display the preprint in perpetuity.

It is made available under a CC-BY-ND 4.0 International license .

156 participant is given feedback on timing and correctness. This assessment is used to measure

157 response inhibition and speed of information processing.

\subsubsection{Mild Behavioral Impairment Checklist}

160 The MBI-C is included in the BHR study partner portal and is therefore completed by an

161 informant. The MBI-C is explicit that symptoms are de novo in later life, represent a change

162 from longstanding patterns of behavior, and are persistent for at least six months. The MBI-C

163 consists of questions in the five MBI domains of apathy, mood and anxiety, agitation and

164 impulsivity, impaired social cognition, and psychosis, with items geared towards capturing NPS

165 in community dwelling, functionally independent, non-demented older adults. The scale takes

$166 \sim 7-8$ minutes to complete, consisting of 34 questions; scoring is from 0-3, representing absent,

167 mild, moderate, and severe changes, with a total score range of $0-102^{28}$.

$169 \quad 2.4$ Statistical Analysis

170 Continuous demographic variables (age and years of education) were analyzed using

171 independent sample t-tests to compare MBI+ and MBI- groups; sex distribution between the two

172 groups was analyzed using chi-square tests. MBI-C was dichotomized based on a validation in

173 primary care non-demented older adults in which scores of $>7$ differentiated MBI+ from MBI-

174 with a sensitivity of 0.93 , specificity of 0.76 and AUC of $0.93^{37}$. As exploratory analyses,

175 cutpoints of $>5$ and $>6$ were also analyzed. Univariate Analysis of Covariance (ANCOVA) was

176 used to compare performance on Lumosity cognitive tests between MBI+ and MBI- groups,

177 covarying for age, sex, education, and neuropsychological and neurobehavioral assessment

178 interval. Skewed data were log-transformed, however the TMT response time variable was 
medRxiv preprint doi: https://doi.org/10.1101/2021.07.19.21260787; this version posted July 22, 2021. The copyright holder for this preprint (which was not certified by peer review) is the author/funder, who has granted medRxiv a license to display the preprint in perpetuity.

It is made available under a CC-BY-ND 4.0 International license .

analyzed with a negative binomial regression due a skewed distribution with an overrepresentation of zeros. For Go/No-Go errors, ordinal logistic regression was performed because the response variable only had three possible values: 0,1 , and 2 .

Additionally, negative binomial regressions were fitted to assess Lumosity task prediction of MBI-C total scores. Negative binomial regression is preferred when the data are skewed, as in this sample where the mode on the MBI-C is zero indicating no emergent and persistent NPS. Lumosity task measures as continuous scores were the independent variables in these models. The covariates included were age, sex, education, and neuropsychological and neurobehavioral assessment interval. The $p$ values for Lumosity task measures were calculated using likelihood ratio tests.

Statistical analyses were performed using SPSS v26 and R 3.6.2.

\section{$\underline{3 \text { Results }}$}

Participant selection is described in Figure 1. The final sample included 499 participants with a mean age of 67 (SD 10.4), of which 308/499 were females (61\%) (Table 1). The number of MBI+ participants was $31(6.2 \%)$ (Figure 1). A significantly greater number of men were classified as $\mathrm{MBI}+(64 \%, \mathrm{p}=0.002) . \mathrm{MBI}+$ participants had significantly poorer forward memory span (mean sequence length of 4.68 vs. 5.26, $\mathrm{p}=0.005$; Figure $2 \mathrm{a}$ ), poorer reverse memory span (3.81 vs. $4.85, \mathrm{p}<0.0001$; Figure $2 \mathrm{~b}$ ), more TMT errors ( 4.29 vs. $1.85, \mathrm{p}=0.01$; Figure $2 \mathrm{c}$ ), and longer TMT completion time (67.67 vs. 45.08 seconds, $p<0.0001$; Figure $2 \mathrm{~d}$ ). MBI was not associated with the number of errors $(\mathrm{p}=0.84)$ and response time $(\mathrm{p}=0.16)$ on the Go/No-Go task (Figures 2e \& 2f). The effect sizes for these differences were modest. Of the tests that significantly differed between groups, the largest effect size (Cohen's $f$ ) was for reverse memory 
medRxiv preprint doi: https://doi.org/10.1101/2021.07.19.21260787; this version posted July 22, 2021. The copyright holder for this preprint (which was not certified by peer review) is the author/funder, who has granted medRxiv a license to display the preprint in perpetuity.

It is made available under a CC-BY-ND 4.0 International license .

202 span (0.20), followed by TMT response time (0.20), memory span (0.13), and TMT accuracy

203 (0.11). See Tables 2-4 for statistical reporting. Analyses using cutpoints of $>5$ and $>6$ for MBI-C

204 show very similar results and are included in supplemental tables (Supplemental tables 1-6).

205 Negative binomial regressions utilizing Lumosity scores to predict MBI score determined

206 that worse memory $\operatorname{span}\left(X^{2}(1, \mathrm{~N}=499)=6.6, \mathrm{p}=0.01\right)$, worse reverse memory $\operatorname{span} X^{2}(1$,

$207 \mathrm{~N}=498)=5.4,(\mathrm{p}=0.02)$, more TMT errors $\left(X^{2}(1, \mathrm{~N}=499)=5.8, \mathrm{p}=0.02\right)$ and longer TMT response

208 time $\left(X^{2}(1, \mathrm{~N}=499)=9.6, \mathrm{p}=0.002\right)$ were all associated with higher MBI-C total scores. Go/No-

209 Go errors $\left(X^{2}(1, \mathrm{~N}=497)=0.16, \mathrm{p}=0.69\right)$ and $\mathrm{Go} /$ No-Go response time $\left(X^{2}(1, \mathrm{~N}=497)=0.97\right.$,

$210 \mathrm{p}=0.33$ ) were not associated with MBI-C score (Table 5).

\section{$212 \underline{4 \text { Discussion }}$}

213 In a sample of 499 participant dyads in BHR, we demonstrated the feasibility of delivering

214 unsupervised online assessments of behavioral and cognitive markers of dementia risk. Utilizing

215 the validated cut off score of $>7$ on the MBI-C, MBI+ status was associated with significant

216 differences in memory and executive function, measured using memory span, reverse memory

217 span, TMT errors and TMT speed. Further, significant associations were found between poorer

218 objectively measured cognitive performance, in the domains of memory and executive function,

219 and MBI symptom severity. Effect sizes were small, ranging from 0.11-0.20. The findings do

220 suggest that a simple informant reported behavioral measure completed via an online portal

221 might be a relevant addition to neuropsychological testing, warranting further study in BHR. In

222 other work, MBI+ status has demonstrated significant and meaningful associations with incident

223 cognitive decline and dementia across several studies, settings, and populations ${ }^{20-26}$. Thus, while 
medRxiv preprint doi: https://doi.org/10.1101/2021.07.19.21260787; this version posted July 22, 2021. The copyright holder for this preprint (which was not certified by peer review) is the author/funder, who has granted medRxiv a license to display the preprint in perpetuity.

It is made available under a CC-BY-ND 4.0 International license .

224 convergent with tests of memory and executive function, behavioral and cognitive markers of

225 risk may be distinct, potentially offering complementary measures of risk.

227 Our data indicate that the BHR is an effective platform to conduct remote assessments of

228 cognitive functioning with convergence of behavioral and cognitive tests. Poorer performance on

229 unsupervised online neuropsychological testing has been associated with self-report MCI and

$230 \mathrm{AD}^{8}$. Online participant testing is an efficient and reliable tool for neuropsychological testing,

231 which can identify performance decrements in executive dysfunction and memory ${ }^{32}$. Similarly,

232 online informant reports such as those collected in the BHR study partner portal are valuable and

233 informative. Online study-partner reported cognitive decline is comparable to data collected in

234 clinic, is associated with objectively defined participant cognition ${ }^{35}$, and is associated with

235 amyloid, clinical diagnosis of dementia due to AD, and in-clinic cognitive screening test $\operatorname{scores}^{5}$.

236 In our study, online informant-reported behavioral symptoms associated with differences in

237 memory and executive function collected via the participant portal. This harmonized utilization

238 of participant and study partner portals is effective and can allow continuation of research

239 activities even during trying times such as the recent pandemic, where consistent in person visits

240 between clinicians and patients were not feasible. Although the COVID-19 pandemic has

241 highlighted the need for alternative infrastructure to allow continued care, the tools that have

242 been developed may permit the assessment of older adults who for physical, social, or cognitive

243 reasons could not previously access care. This approach also allows outreach to areas less

244 accessible to academic centers. 
medRxiv preprint doi: https://doi.org/10.1101/2021.07.19.21260787; this version posted July 22, 2021. The copyright holder for this preprint (which was not certified by peer review) is the author/funder, who has granted medRxiv a license to display the preprint in perpetuity.

It is made available under a CC-BY-ND 4.0 International license.

246 The cognitive domain differences detected with the MBI-C include memory and executive

247 function, which are relevant and important for AD risk ${ }^{38}$. Early decline in memory and executive

248 function has been shown to be associated with the preclinical disease process, thus, early

249 detection of reductions in cognitive functioning may be useful in identifying populations at

250 risk $^{39,40}$. Both memory and executive function are important endpoints in AD trials ${ }^{41}$.

251 Longitudinal cohorts have demonstrated that an acceleration of decline in memory performance

252 occurs 3-4 years before a diagnosis of MCI and 7 years before a diagnosis of AD, while for

253 executive function an accelerated decline occurs 2-3 years before AD diagnosis ${ }^{42,43}$. The finding

254 of small but significant associations between MBI and poorer memory and executive function

255 performance is consistent with the evolving description of the cognitive profile of $\mathrm{MBI}^{44-46}$.

256 These findings are consistent with a previous study using the UK online PROTECT study portal

257 in which self-reported MBI, measured with the MBI-C, was associated with faster decline in

258 attention and working memory at one year in older adults with normal cognition ${ }^{20}$. A subsequent

259 analysis of cognitively normal PROTECT participants, with a median follow up time of 3 years,

260 demonstrated an association between baseline informant-reported MBI+ status and decline in

261 measures of working memory and fluid intelligence ${ }^{26}$. In an overlapping sample, AD genetic risk

262 was determined using polygenic risk scores. AD genetic risk was associated with worse

263 cognition in the informant-reported MBI+ group but not in the MBI- group. The strongest

264 association was in those with more severe MBI, aged $\geq 65^{47}$. These convergent findings support

265 leveraging online cognitive and behavioral measures to explore dementia risk. In a recent study

266 of National Alzheimer Coordinating Center data, the combination of informant-reported MBI

267 and subjective cognitive decline (SCD) had a greater risk of incident cognitive and functional

268 decline at three years compared to either MBI or SCD alone ${ }^{24}$. Further, in a subsequent study, 
medRxiv preprint doi: https://doi.org/10.1101/2021.07.19.21260787; this version posted July 22, 2021. The copyright holder for this preprint (which was not certified by peer review) is the author/funder, who has granted medRxiv a license to display the preprint in perpetuity.

It is made available under a CC-BY-ND 4.0 International license .

those with SCD and MBI together had a shorter median time to incident MCI compared to those with SCD in the absence of $\mathrm{MBI}^{48}$. Taken together the results suggest that individuals with subtle

271 neuropsychological test score differences and MBI together may be at higher risk for cognitive

272 and functional decline.

274 As the case ascertainment instrument developed to measure MBI in accordance with the

275 ISTAART-AA MBI criteria, the MBI-C was designed to: 1) operationalize the MBI concept; 2)

276 measure a selected list of NPS which may help identify preclinical or prodromal dementia; and

277 3) predict risk of several dementias ${ }^{28}$. This instrument has been validated in an online cohort of

278 cognitively normal older adults ${ }^{27}$, a primary care sample with $\mathrm{SCD}^{29}$ or $\mathrm{MCI}^{49}$, and a cognitive

279 neurology clinic population with SCD and $\mathrm{MCI}^{50}$.

281 However, limitations in our study may affect interpretation and generalizability. These

282 limitations include high education levels and restriction to participants and study-partners who

283 can successfully complete tasks online ${ }^{35}$. Since the BHR is an online self-report database, the

284 lack of a clinical diagnosis within the sample group is a potential source of error. BHR

285 participants may have undiagnosed and/or unreported neurodegenerative disease or psychiatric

286 disorders, which may be associated with greater MBI score. While online cognitive testing has

287 been validated ${ }^{8,33}$, further research is needed, given the lack of supervision or control for test

288 environment, external factors, distractors, or cues. Further, we were not able to control for

289 important disease related factors such as severity and time since symptom onset. Although MBI

290 was associated with statistically significant differences in Lumosity neuropsychological test

291 scores, effect sizes were small, and the clinical significance of these differences is difficult to 
medRxiv preprint doi: https://doi.org/10.1101/2021.07.19.21260787; this version posted July 22, 2021. The copyright holder for this preprint (which was not certified by peer review) is the author/funder, who has granted medRxiv a license to display the preprint in perpetuity.

It is made available under a CC-BY-ND 4.0 International license .

292 interpret in the largely cognitively healthy population enrolled in BHR. Our data are promising

293 but not conclusive, and further research is required. Whether these small differences in cognitive

294 test scores represent greater risk for incident cognitive decline and dementia can be addressed in

295 the future using longitudinal data and a cohort that includes participants with cognitive

296 impairment.

297

298 In summary, in this BHR study combining self- and informant-rated measures, we observed the

299 convergence of behavioral risk markers for dementia and cognitive differences, reflected by

300 neuropsychological tests incorporating memory and executive function. The findings lend

301 additional support to online unsupervised administration of cognitive and neuropsychiatric

302 measures, as a low-cost approach to improve access to neurocognitive assessments, potentially

303 identifying at-risk older adults.

305 Acknowledgements

306 Data used in this study were collected using the BHR, which is funded by the NIH, Alzheimer's

307 Association, Alzheimer's Drug Discovery Foundation, California Department of Public Health,

308 Connie and Kevin Shanahan, The Drew Foundation, General Electric, Global Alzheimer's

309 Platform Foundation, Larry L. Hillbolm Foundation, The Ray and Dagmar Dolby Family Fund,

310 The Rosenberg Alzheimer's Project and Patient-Centered Outcomes Research Institute.

312 FK, HC, AW, TW have no interests to declare. ZI is funded by the Canadian Institutes of Health

313 Research, and has received consulting fees/honoraria from Otsuka/Lundbeck, outside the

314 submitted work. His institution has received funds from Acadia, Biogen, Roche, and Sunovion, 
medRxiv preprint doi: https://doi.org/10.1101/2021.07.19.21260787; this version posted July 22, 2021. The copyright holder for this preprint (which was not certified by peer review) is the author/funder, who has granted medRxiv a license to display the preprint in perpetuity.

It is made available under a CC-BY-ND 4.0 International license .

315 also outside the submitted work. RLN is a co-investigator for the BHR. RSM has received grant

316 funding from the National Institute of Mental Health and has received research support from

317 Johnson \& Johnson. MWW receives support for his work from the following: National Institute

318 of Health, Department of Defense, Patient-Centered Outcomes Research Institute, California

319 Department of Public Health, University of Michigan, Siemens, Biogen, Larry L. Hillbolm

320 Foundation, Alzheimer's Association, The State of California, Johnson \& Johnson, Kevin and

321 Connie Shanahan, GE, Vrije Universiteit Medical Center Amsterdam, Australian Catholic

322 University, The Stroke Foundation and the Veterans Administration. He has served on the

323 Advisory Boards for Eli Lilly, Cerecin/Accera, Roche, Alzheon, Inc., and BHR.

\section{HIGHLIGHTS}

326 - Online portals for older adults and study partners can be used for dementia risk

$327 \quad$ assessment

328 - This approach is useful when in-person assessments are not feasible (physical, social,

329 cognitive or health systems-realted (e.g., the COVID-19 pandemic))

330 - The relationship between mild behavioral impairment (MBI) and cognition in older

$331 \quad$ adults was explored

332 - MBI was associated with small magnitude, but significantly poorer performance in

333 memory and executive function, and may serve as a complementary measure of risk 


\section{Identification}

1501 unique participant IDs with collected MBI-C in BHR

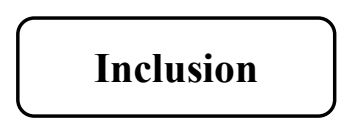

Included in the study $(n=499)$

\section{Excluded participants with} developmental disorders, mental disorders and medical conditions and participants without medical records (n $=586$; 915 remained)

Excluded participants whose Lumosity cognitive tests were not collected $(\mathrm{n}=$ $113 ; 802$ remained)

Excluded participants whose Lumosity cognitive tests and MBI-C were not collected within a year $(n=416 ; 499$ remained)

\section{Figure 1 - Flowchart of participants from the BHR included for analysis}


361 Table 1. Summary statistics for demographics

$$
\text { Cutpoint of MBI-C > } 7
$$

MBI+ $(n=31) \quad$ MBI- $(n=468) \quad \begin{aligned} & \text { Test } \\ & \text { Statistic }\end{aligned}$

Average Age

69.52

67.11

$t(497)=1 \quad .213$

.25

Average Estimated Years of 17.58

17.14

$t(497)=1 \quad .260$

Education

11

297

Percentage of Female

$35.48 \%$

$63.46 \%$

$\chi^{2}=9.63$

.002

\section{Table 2. Summary statistics for Lumosity tasks (ANCOVA)}

\section{Partial}

\begin{tabular}{|c|c|c|c|c|c|c|c|}
\hline Cognitive Measures & $\begin{array}{l}\text { Mean } \\
(\mathrm{MBI}+)\end{array}$ & $\begin{array}{l}\text { Mean } \\
\text { (MBI-) }\end{array}$ & $\boldsymbol{F}$ & $\begin{array}{l}d f \\
\text { within }\end{array}$ & $\begin{array}{l}d f \\
\text { between }\end{array}$ & $\begin{array}{c}\eta^{2} \\
\text { (effect } \\
\text { size) }\end{array}$ & P Value \\
\hline \multicolumn{8}{|l|}{ Cutpoint of MBI-C $>7$} \\
\hline Memory Span & 4.68 & 5.26 & 8.11 & 1 & 493 & $\begin{array}{l}0.016 \\
(0.13)\end{array}$ & 0.0046 \\
\hline Reverse Memory Span & 3.81 & 4.85 & 20.06 & 1 & 492 & $\begin{array}{l}0.039 \\
(0.20)\end{array}$ & $<0.0001$ \\
\hline Trailmaking Errors & 4.29 & 1.85 & 6.81 & 1 & 493 & $\begin{array}{l}0.014 \\
(0.11)\end{array}$ & 0.0093 \\
\hline $\begin{array}{l}\text { Trailmaking Response } \\
\text { Time (log transformed) }\end{array}$ & 67.67 & 45.08 & 19.40 & 1 & 493 & $\begin{array}{l}0.038 \\
(0.20)\end{array}$ & $<0.0001$ \\
\hline Go/No-Go Errors & 0.71 & 0.64 & 0.04 & 1 & 491 & $\begin{array}{l}0.000 \\
(0.01)\end{array}$ & 0.8386 \\
\hline Go/No-Go Response Time & 496.42 & 473.87 & 1.98 & 1 & 491 & $\begin{array}{l}0.004 \\
(0.06)\end{array}$ & 0.1604 \\
\hline
\end{tabular}


medRxiv preprint doi: https://doi.org/10.1101/2021.07.19.21260787; this version posted July 22, 2021. The copyright holder for this preprint (which was not certified by peer review) is the author/funder, who has granted medRxiv a license to display the preprint in perpetuity.

It is made available under a CC-BY-ND 4.0 International license .

Table 3. Summary statistics for using MBI-C status (Cutpoint of 7) to predict Trail Making Errors (Negative Binomial Regression)

\begin{tabular}{lcccr}
\hline Outcome & Beta & $95 \%$ CI & $X^{2}$ & $p$ value \\
\hline Trail Making Errors & $137.5 \%$ & $+13.1 \%$ to $+484.0 \%$ & 5.312 & $\mathbf{0 . 0 2 1 2}$ \\
\hline
\end{tabular}

$374{ }^{1}$ Beta coefficients represent the estimate percent difference in Trail Making errors associated 375 with

376 status

Table 4. Summary statistics for using MBI-C status (Cutpoint of 7) to predict Go/No-Go Errors (Ordinal Logistic Regression)

\begin{tabular}{lccc}
\hline Outcome & Odds Ratio & $95 \%$ CI & $p$ value \\
\hline GoNoGo Errors & 1.058 & 0.517 to 2.121 & 0.875 \\
\hline
\end{tabular}

381 Table 5. Summary statistics for Lumosity tasks predicting MBI-C total score

\begin{tabular}{lcccc}
\hline Predictor & Beta & $95 \%$ CI & $X^{2}$ & $p$ value \\
\hline Memory Span & $-26.2 \%$ & $-41.8 \%$ to $-7.1 \%$ & 6.6513 & $\mathbf{0 . 0 0 9 9}$ \\
Reverse Memory Span & $-15.7 \%$ & $-27.7 \%$ to $-2.6 \%$ & 5.3765 & $\mathbf{0 . 0 2 0 4}$ \\
Trail Making Errors & $5.3 \%$ & $+0.9 \%$ to $+11.2 \%$ & 5.8059 & $\mathbf{0 . 0 1 6 0}$ \\
Trail Making Response Time & $0.0012 \%$ & $+0.0004 \%$ to $+0.0023 \%$ & 9.6268 & $\mathbf{0 . 0 0 1 9}$ \\
GoNoGo Errors & $-6.2 \%$ & $-31.0 \%$ to $+29.0 \%$ & 0.1594 & 0.6897 \\
GoNoGo Response Time & $0.1 \%$ & $-0.2 \%$ to $+0.5 \%$ & 0.9678 & 0.3252 \\
\hline
\end{tabular}

$382{ }^{1}$ Beta coefficients represent the estimate percent difference in total MBI-C score given one unit 383 change in Lumosity task measure. 
medRxiv preprint doi: https://doi.org/10.1101/2021.07.19.21260787; this version posted July 22, 2021. The copyright holder for this preprint (which was not certified by peer review) is the author/funder, who has granted medRxiv a license to display the preprint in perpetuity.

It is made available under a CC-BY-ND 4.0 International license .

Memory Span

389

390

391

392

393

394

395

396

397

398

399

400

401

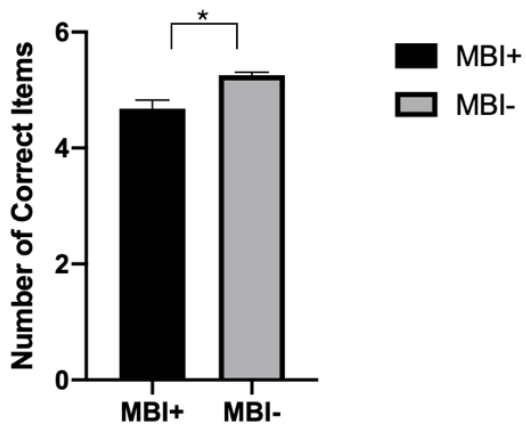

Figure $2 a$, Positive result (>7) on the MBI-C is associated with shorter memory span

\section{Trailmaking Errors}

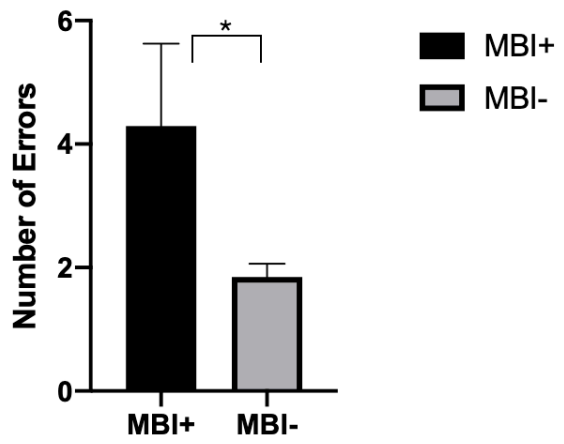

Figure $2 c$, Positive result (>7) on the MBI-C is associated with more errors in the Trailmaking-B task

$4 U<$

\section{GoNoGo Errors}

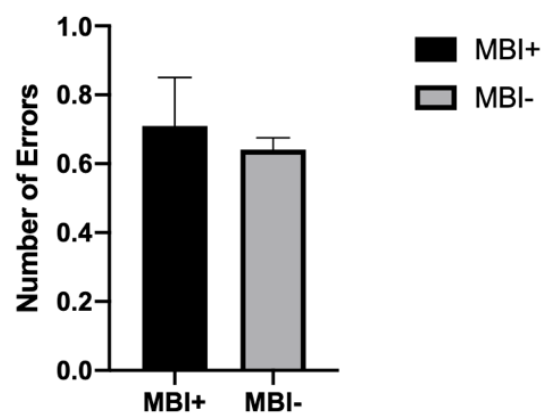

Figure $2 e$, Positive result (>7) on the $\mathrm{MBI}-\mathrm{C}$ is not associated with the number of errors on a GoNoGo task

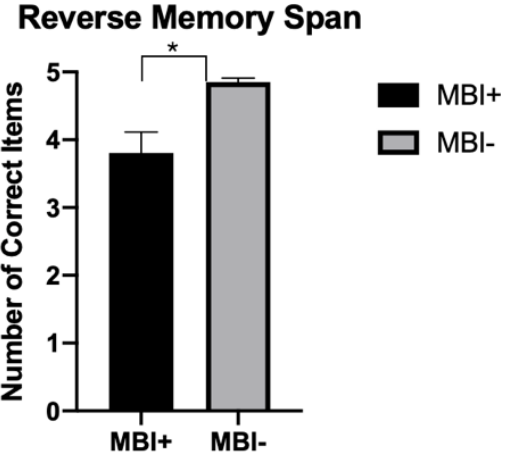

Figure $2 b$, Positive result (>7) on the MBI-C is associated with shorter reverse memory span

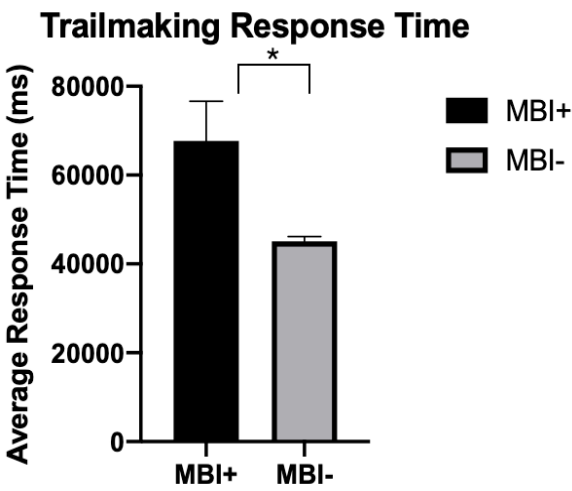

Figure 2d, Positive result (>7) on the MBI-C is associated with longer response time in

Trailmaking- $B$ task

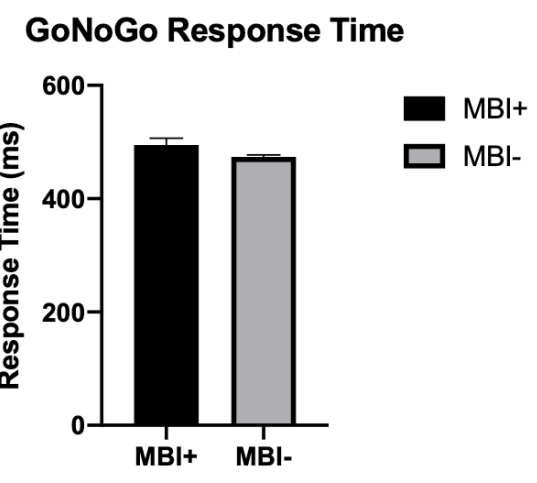

Figure $2 f$, Positive result (>7) on the $\mathrm{MBI}-\mathrm{C}$ is not associated with the response time on a GoNoGo task 
medRxiv preprint doi: https://doi.org/10.1101/2021.07.19.21260787; this version posted July 22, 2021. The copyright holder for this preprint (which was not certified by peer review) is the author/funder, who has granted medRxiv a license to display the preprint in perpetuity. It is made available under a CC-BY-ND 4.0 International license .

References:

411 1. Marsden G, Mestre-Ferrandiz J. Dementia: The R\&D Landscape. 2015.

412 2. Cummings J, Reiber C, Kumar P. The price of progress: Funding and financing Alzheimer's disease drug development. Alzheimer's \& Dementia: Translational Research \& Clinical Interventions. 2018;4:330-343.

3. Gauthier S, Albert M, Fox N, et al. Why has therapy development for dementia failed in the last two decades? Alzheimers \& Dementia. 2016;12(1):60-64.

4. Mortby ME, Black SE, Gauthier S, et al. Dementia clinical trial implications of Mild Behavioral Impairment. Int Psychogeriatr. 2018;30(2):171-175.

5. Nosheny RL, Camacho MR, Jin C, et al. Validation of online functional measures in cognitively impaired older adults. Alzheimer's \& Dementia. 2020;16(10):1426-1437.

6. Brooker H, Williams G, Hampshire A, et al. FLAME: A computerized neuropsychological composite for trials in early dementia. Alzheimers Dement (Amst). 2020;12(1):e12098.

7. Papp KV, Rentz DM, Maruff P, et al. The computerized cognitive composite (c3) in a4, an alzheimer's disease secondary prevention trial. The journal of prevention of Alzheimer's disease. 2021;8(1):59-67.

8. Mackin RS, Insel PS, Truran D, et al. Unsupervised online neuropsychological test performance for individuals with mild cognitive impairment and dementia: results from the Brain Health Registry. Alzheimers Dement (Amst). 2018;10:573-582.

9. Perin S, Buckley RF, Pase MP, et al. Unsupervised assessment of cognition in the Healthy Brain Project: Implications for web-based registries of individuals at risk for Alzheimer's disease. Alzheimer's \& Dementia: Translational Research \& Clinical Interventions. 2020;6(1): e12043.

10. Lanctôt KL, Amatniek J, Ancoli-Israel S, et al. Neuropsychiatric signs and symptoms of Alzheimer's disease: New treatment paradigms. Alzheimer's \& Dementia: Translational Research \& Clinical Interventions. 2017;3:440-449.

11. Wise EA, Rosenberg PB, Lyketsos CG, Leoutsakos J-M. Time course of neuropsychiatric symptoms and cognitive diagnosis in National Alzheimer's Coordinating Centers volunteers. Alzheimers Dement (Amst). 2019;11:333-339.

12. Ismail Z, Smith EE, Geda Y, et al. Neuropsychiatric symptoms as early manifestations of emergent dementia: provisional diagnostic criteria for mild behavioral impairment. Alzheimer's \& Dementia. 2016;12(2):195-202.

13. Andrews SJ, Ismail Z, Anstey KJ, Mortby M. Association of Alzheimer's genetic loci with mild behavioral impairment. Am J Med Genet B Neuropsychiatr Genet. 2018;177(8):727-735.

14. Creese B, Brooker H, Aarsland D, Corbett A, Ballard C, Ismail Z. Genetic risk for Alzheimer disease, cognition and Mild Behavioral Impairment in healthy older adults. Alzheimer's \& Dementia: DADM. 2021;in press:2020.2005.2013.20100800.

15. Johansson M, Stomrud E, Insel P, et al. Mild Behavioral Impairment and its relation to tau pathology in preclinical Alzheimer's disease. Transl Psychiatry. 2021;11(76).

16. Lussier FZ, Pascoal TA, Chamoun M, et al. Mild behavioral impairment is associated with $\beta$-amyloid but not tau or neurodegeneration in cognitively intact elderly individuals. Alzheimer's \& Dementia. 2020;16:192-199.

17. Naude J, Gill S, Hu S, et al. Plasma Neurofilament Light: a marker of cognitive decline in Mild Behavioural Impairment. J Alzheimers Dis. 2020;76(3):1017-1027. 
medRxiv preprint doi: https://doi.org/10.1101/2021.07.19.21260787; this version posted July 22, 2021. The copyright holder for this preprint (which was not certified by peer review) is the author/funder, who has granted medRxiv a license to display the preprint in perpetuity. It is made available under a CC-BY-ND 4.0 International license .

456 18. Gill S, Wang M, Mouches P, et al. Neural Correlates of the Impulse Dyscontrol Domain of Mild Behavioral Impairment. Int J Geriatr Psychiatry. 2021;in press.

19. Matuskova V, Ismail Z, Nikolai T, et al. Mild behavioral impairment is associated with atrophy of entorhinal cortex and hippocampus in a memory clinic cohort. Frontiers in Aging Neuroscience. 2021;13:236.

20. Creese B, Brooker H, Ismail Z, et al. Mild Behavioral Impairment as a Marker of Cognitive Decline in Cognitively Normal Older Adults. The American Journal of Geriatric Psychiatry. 2019;27(8):823-834.

21. Gill S, Mouches $\mathrm{P}, \mathrm{Hu}$ S, et al. Using Machine Learning to Predict Dementia from Neuropsychiatric Symptom and Neuroimaging Data. J Alzheimers Dis. 2020;75(1):277288.

22. Matsuoka T, Ismail Z, Narumoto J. Prevalence of mild behavioral impairment and risk of dementia in a psychiatric outpatient clinic. J Alzheimers Dis. 2019;70(2):505-513.

23. Taragano FE, Allegri RF, Heisecke SL, et al. Risk of Conversion to Dementia in a Mild Behavioral Impairment Group Compared to a Psychiatric Group and to a Mild Cognitive Impairment Group. J Alzheimers Dis. 2018;62:227-238.

24. Ismail Z, McGirr A, Gill S, Hu S, Forkert ND, Smith EE. Mild Behavioral Impairment and Subjective Cognitive Decline predict Cognitive and Functional Decline. J Alzheimers Dis. 2021;80:459-469.

25. Tsunoda K, Yamashita T, Osakada Y, et al. Positive baseline behavioral and psychological symptoms of dementia predict a subsequent cognitive impairment in cognitively normal population. Neurology and Clinical Neuroscience. 2021.

26. Wolfova K, Creese B, Aarsland D, et al. Sex differences in the association of mild behavioral impairment with cognitive aging. medRxiv. 2021.

27. Creese B, Griffiths A, Brooker H, et al. Profile of mild behavioral impairment and factor structure of the mild behavioral impairment checklist in cognitively normal older adults. Int Psychogeriatr. 2020;32(6):705-717.

28. Ismail Z, Aguera-Ortiz L, Brodaty H, et al. The Mild Behavioral Impairment Checklist (MBI-C): A Rating Scale for Neuropsychiatric Symptoms in Pre- Dementia Populations. Journal of Alzheimers Disease. 2017;56(3):929-938.

29. Mallo SC, Ismail Z, Pereiro AX, et al. Assessing mild behavioral impairment with the mild behavioral impairment checklist in people with subjective cognitive decline. Int Psychogeriatr. 2019;31(2):231-239.

30. Saari T, Smith EE, Ismail Z. Network analysis of impulse dyscontrol in mild cognitive impairment and subjective cognitive decline. Int Psychogeriatr. 2021:1-10.

31. Weiner MW, Nosheny R, Camacho M, et al. The Brain Health Registry: An internetbased platform for recruitment, assessment, and longitudinal monitoring of participants for neuroscience studies. Alzheimer's \& Dementia. 2018;14(8):1063-1076.

32. Morrison GE, Simone CM, Ng NF, Hardy JL. Reliability and validity of the NeuroCognitive Performance Test, a web-based neuropsychological assessment. Front Psychol. 2015;6:1652.

33. Lim YY, Pietrzak RH, Bourgeat P, et al. Relationships between performance on the Cogstate Brief Battery, neurodegeneration, and $\mathrm{A} \beta$ accumulation in cognitively normal older adults and adults with MCI. Arch Clin Neuropsychol. 2015;30(1):49-58.

34. Ashford JW, Gere E, Bayley PJ. Measuring memory in large group settings using a continuous recognition test. J Alzheimers Dis. 2011;27(4):885-895. 
medRxiv preprint doi: https://doi.org/10.1101/2021.07.19.21260787; this version posted July 22, 2021. The copyright holder for this preprint

(which was not certified by peer review) is the author/funder, who has granted medRxiv a license to display the preprint in perpetuity.

It is made available under a CC-BY-ND 4.0 International license .

35. Nosheny RL, Camacho MR, Insel PS, et al. Online study partner-reported cognitive decline in the Brain Health Registry. Alzheimer's \& Dementia: Translational Research \& Clinical Interventions. 2018;4:565-574.

36. Milner B. Interhemispheric differences in the localization of psychological processes in man. Br Med Bull. 1971.

37. Mallo SC, Pereiro AX, Ismail Z, et al. Mild Behavioral Impairment Checklist (MBI-C): A Preliminary Validation Study. Alzheimers Dement. 2018;14(7 supplement).

38. Wilson RS, Leurgans SE, Boyle PA, Bennett DA. Cognitive decline in prodromal Alzheimer disease and mild cognitive impairment. Arch Neurol. 2011;68(3):351-356.

39. Nagata T, Shinagawa S, Ochiai Y, et al. Association between executive dysfunction and hippocampal volume in Alzheimer's disease. Int Psychogeriatr. 2011;23(5):764-771.

40. Almkvist O, Basun H, Bäckman L, et al. Mild cognitive impairment - an early stage of Alzheimer's disease? In: Alzheimer's Disease —From Basic Research to Clinical Applications. Springer; 1998:21-29.

41. Vellas B, Andrieu S, Sampaio C, Coley N, Wilcock G. Endpoints for trials in Alzheimer's disease: a European task force consensus. The Lancet Neurology. 2008;7(5):436-450.

42. Mistridis P, Krumm S, Monsch AU, Berres M, Taylor KI. The 12 years preceding mild cognitive impairment due to Alzheimer's disease: the temporal emergence of cognitive decline. J Alzheimers Dis. 2015;48(4):1095-1107.

43. Grober E, Hall CB, Lipton RB, Zonderman AB, Resnick SM, Kawas C. Memory impairment, executive dysfunction, and intellectual decline in preclinical Alzheimer's disease. J Int Neuropsychol Soc. 2008;14(2):266-278.

44. Rouse HJ, Small BJ, Schinka JA, Loewenstein DA, Duara R, Potter H. Mild behavioral impairment as a predictor of cognitive functioning in older adults. Int Psychogeriatr. 2020:1-9.

45. Yoon E, Ismail Z, Hanganu A, et al. Mild Behavioral Impairment is linked to worse cognition and brain atrophy in Parkinson's disease. Neurology. 2019;93(8):e766-e777.

46. Wong F, Ng KP, Yatawara C, Low A, Ismail Z, Kandiah N. Characterising mild behavioural impairment in Asian mild cognitive impairment and cognitively normal individuals: Neuropsychiatry and behavioral neurology: Neuropsychiatric symptoms in MCI and dementia. Alzheimer's \& Dementia. 2020;16:e45059.

47. Creese B, Arathimos R, Brooker H, et al. Genetic risk for Alzheimer's disease, cognition, and mild behavioral impairment in healthy older adults. Alzheimers Dement (Amst). 2021;13(1):e12164.

48. Nathan S, Gill S, Ismail Z. APOE $\varepsilon 4$ status in pre-dementia risk states, mild behavioural impairment and subjective cognitive decline, and the risk of incident cognitive decline. Paper presented at: 2020 Alzheimer's Association International Conference2020.

49. Mallo SC, Ismail Z, Pereiro AX, et al. Assessing mild behavioral impairment with the Mild behavioral impairment-checklist in people with mild cognitive impairment. $J$ Alzheimers Dis. 2018;66(1):83-95.

50. Hu S, Patten SB, Fick G, Smith EE, Ismail Z. VALIDATION OF THE MILD BEHAVIORAL IMPAIRMENT CHECKLIST (MBI-C) IN A CLINIC-BASED SAMPLE. Alzheimer's \& Dementia: The Journal of the Alzheimer's Association. 2019;15(7):P365. 